Oncologist. 2008 December ; 13(12): 1255-1269. doi:10.1634/theoncologist.2008-0207.

\title{
Carcinoid Tumors
}

\author{
Scott N. Pinchot, MD, Kyle Holen, MD, Rebecca S. Sippel, MD, and Herbert Chen, MD, \\ FACS $^{\star}$ \\ Section of Endocrine Surgery, Department of Surgery, and Section of Hematology and Oncology, \\ Department of Medicine, University of Wisconsin, Madison, WI
}

\begin{abstract}
Carcinoid tumors are rare, slow-growing neuroendocrine tumors arising from the enterochromaffin cells disseminated throughout the gastrointestinal and bronchopulmonary systems. Though they have been traditionally classified based upon the embryologic site of origin, morphologic pattern, and silver affinity, newer classification systems have been developed to emphasize the considerable clinical and histopathologic variability of carcinoid tumors found within each embryologic site of origin. These neoplasms pose a diagnostic challenge because they are often innocuous at the time of presentation, emphasizing the need for a multidisciplinary diagnostic approach utilizing biochemical analysis, standard cross-sectional imaging, and newer advances in nuclear medicine. Similarly, treatment of both primary and disseminated carcinoid disease reflects the need for a multidisciplinary approach, with surgery remaining the only curative modality. The prognosis for patients with these tumors is generally favorable, however can be quite variable and is related to the location of the primary tumor, extent of metastatic disease at initial presentation, and the time of diagnosis.
\end{abstract}

\section{Keywords}

Carcinoid cancer; neuroendocrine; somatostatin; chromogranin A; serotonin

\section{Introduction}

\section{Historical Background}

Although Theodor Langhans (1839-1915) was the first to describe the histology of a carcinoid tumor in 1867 [1], it is generally Otto Lubarsch (1860-1933) who is credited with the first report of 2 patients with ileal carcinoid tumors discovered at autopsy, in 1888 [2-3]. In 1907, Siegfried Obendorfer (1876-1944), a German pathologist at the University of Munich, coined the term karzinoide, or "carcinoma-like", to describe the unique feature of behaving like a benign tumor despite resembling a carcinoma microscopically [4]. Recognition of the endocrine-related properties of carcinoid tumors did not occur until much later. In 1948, Rapport and colleagues isolated and named serotonin (5-HT), initially identified as a vasoconstrictor substance in the serum [5]; by 1952, it was determined that the origin of this amine was the Kulchitsky cell [6]. Just one year later, Lembeck identified serotonin in an ileal carcinoid and confirmed it as the major hormone responsible for the carcinoid syndrome [7].

\footnotetext{
"Corresponding Author: Herbert Chen, MD, FACS, University of Wisconsin Hospital and Clinics, H4/750 Clinical Science Center, 600 Highland Avenue, Madison, WI 53792, Phone: (608) 263-1387, Fax: (608) 263-7652.

Learning Objectives: (1) Explain the clinical variability of carcinoid tumors based on embryologic site of origin, (2) Describe the multidisciplinary approach to diagnosing and treating patients with carcinoid cancer, (3) Understand signs and symptoms of the carcinoid syndrome and in whom this syndrome is likely to occur
} 


\section{Tumor Biology}

Carcinoids are rare neuroendocrine tumors (NETs) thought to arise from the enterochromaffin cells (Kulchitsky) cells found throughout the crypts of Lieberkühn of the gut [8]. Specifically, the term enterochromaffin refers to the ability to stain with chromium or chrome salts, a common feature of 5-HT-containing cells. Similarly, the granules of carcinoid tumors have a high affinity for silver stains, justifying the use of the nomenclature, argentaffinoma, which had been used interchangeably with carcinoid tumors years ago [3].

The diagnosis of carcinoid tumor is initially based on histology with confirmation by positive immunohistochemical staining, defined as positive staining for one or more neuroendocrine markers (such as chromogranin A or synaptophysin), or electron microscopy in which the cells in most tumors are found to contain membrane-bound secretory granules with dense-core granules in the cytoplasm [9]. Within these granules are a wide variety of biogenic amines and hormones characteristic of NE tumors (Table 1).

The most common biologically active substance secreted from carcinoid tumors is 5-HT (serotonin), a vasoactive peptide whose biosynthesis is accomplished nearly exclusively by the enterochromaffin cells. Synthesized from the amino acid tryptophan, the release of 5-HT into the systemic circulation can cause the classic symptoms of the carcinoid syndrome, which include diarrhea, episodic flushing, bronchoconstriction, and eventual right-sided valvular heart disease [10].

\section{Incidence}

Though relatively rare, carcinoid tumors represent the most common gastrointestinal neuroendocrine tumors [11-14]. In a series of 13,715 carcinoid cases reported to the Surveillance, Epidemiology, and End Results (SEER) program of the National Cancer Institute (NCI), the age-adjusted incidence rates for Caucasian men and women over the last decade were 2.47 and 2.58 per 100,000 population per year, while they were somewhat higher for black men and women (4.48 and 3.98 per 100,000 population per year) [13]. In a separate report from the SEER database of 20,436 carcinoid cases from 1973-2004, carcinoid tumors comprised $0.66 \%$ of all malignancies over this time-frame and demonstrated a $3-10 \%$ increase in tumor incidence depending on the subtype [14]. Overall, the increasing incidence of carcinoid disease is thought to be largely due to the introduction of more sensitive diagnostic tools and an overall increased awareness among physicians [14]; however, the changes in relative incidence may also be due in part to variations in reporting of carcinoid tumors. Benignappearing carcinoid tumors, for instance, were not recorded in the SEER database until 1986 [11]. The increased incidence may also be related to the aging population, given that this is a tumor more common in older adults.

Until recently, carcinoid tumors were thought to be significantly less common than other gastrointestinal tumors. However, in a recent SEER database review of over 35,600 patients, Yao and colleagues [15] demonstrated the prevalence - that is, the number of people alive on a certain date in a population who have never had a diagnosis of that disease-of carcinoid tumors exceeded that of many gastrointestinal tumors. In fact, when compared with other GI neoplasms, the estimated 29-year limited-duration prevalence of NETs was 103,312 in 2004, making these tumors significantly more common than esophageal cancer $(28,664)$, gastric cancer $(65,836)$, pancreatic cancer $(32,353)$, and hepatobiliary cancer $(21,427)$ in the United States [15].

The majority of carcinoids are found within the gastrointestinal tract (55\%) and bronchopulmonary system (30\%) [16]. Population-based statistics have shown that within the gastrointestinal tract, the small intestine is the most common site of carcinoids (45\%), followed 
by the rectum (20\%), appendix (17\%), colon (11\%), and stomach (7\%). Far less common anatomic sites have been reported in the literature, including carcinoids of the breast, larynx, thymus, and gallbladder [17-20]. Traditionally, the appendix had been identified as the most common site of carcinoid tumors within the gastrointestinal tract; however, recent studies suggest the incidence of primary appendiceal carcinoid disease is declining while the incidence of gastric and rectal carcinoid disease is on the rise. This evolution of carcinoid epidemiology presumably stems from improvements in technology and diagnosis over the last several decades, such as improved endoscopic recognition of early, presymptomatic carcinoids in these anatomic locations.

\section{Tumor Classification}

Carcinoid tumors have traditionally been classified based upon the embryologic site of origin, morphologic pattern, and silver affinity. This classification system, originally proposed by Williams and Sandler in 1963 [21], subdivided carcinoids into tumors of the foregut (respiratory tract, thymus, stomach), the midgut (small intestine, appendix, proximal colon), and the hindgut (distal colon, rectum, genitourinary tract). Microscopically, foregut carcinoid tumors characteristically exhibit a trabecular pattern, whereas midgut tumors typically appear as sheets of monotonous polygonal cells [3]. Likewise, the early divisions of carcinoid tumors were based on the staining characteristics when stained with silver. Cells of foregut and rectal tumors accumulate cytoplasmic silver deposits only after being treated with a reducing agent, bestowing the term argyrophil cells. Conversely, the cytoplasm of midgut tumors contains granules which stain black with ammoniacal silver nitrate, which is known as a positive argentaffin reaction [3]. Unfortunately, the clinical behavior of carcinoids within each embryologic division has been shown to vary considerably. For instance, both chronic atrophic gastritis type A (CAG-A)-associated carcinoid tumors and carcinoid tumors associated with multiple endocrine neoplasia type 1 (MEN-1) found within the stomach exhibit an indolent disease course and are rarely associated with the carcinoid syndrome, whereas sporadic gastric carcinoid tumors are often aggressive, displaying a high incidence of metastases and atypical carcinoid syndrome features. As such, many authors have chosen to subdivide carcinoid tumors not only on the site of origin but also on variations in the histologic characteristics of these tumors [22]. Based upon this classification, carcinoid tumors may be characterized as typical or atypical. Typical carcinoids are well-differentiated, exhibiting a distinct recognized histologic pattern (insular, trabecular, glandular, mixed, or undifferentiated) of carcinoid morphology [23]. Conversely, atypical carcinoids may exhibit increased nuclear atypia, focal necrosis, or high mitotic indices.

More recently, the World Health Organization (WHO), in an effort to clarify the classification of carcinoid tumors and to standardize a system that would enable clinicians to compare patients and predict outcomes accurately, proposed a new classification of gastroenteropancreatic neuroendocrine tumors [24]. Based on their malignant potential, the tumors are divided into five main categories: (1) well-differentiated endocrine tumor (proliferation index [PI] less than 2 percent); (2) well-differentiated endocrine carcinoma (PI greater than 2 percent but less than 15 percent); (3) poorly-differentiated endocrine carcinoma (PI greater than 15 percent); (4) mixed exocrine-endocrine tumors; and (5) tumor-like lesions.

Proliferation indices (PI) are typically based upon monoclonal antibody (MIB-1) binding to the Ki-67 antigen, an important marker for cellular proliferation and mitotic activity. The Ki-67 protein is detected in nuclear fractions of proliferating cells in G1, S, G2, and M phases of the cell cycle; however, quiescent cells in G0 do not express the antigen. Interestingly, several recent retrospective studies have identified the Ki-67 labeling index as an important independent predictor of carcinoid tumor biological behavior and patient survival [25-26]. Several single-institution experiences with carcinoid tumors have demonstrated a correlation 
between low Ki-67 values and longer survival. Likewise, mean Ki-67 values were found to be significantly less in benign versus malignant tumors, and poorly differentiated tumors were characterized by very high Ki-67 indices which all exceeded 14\% [27]. Based on these studies that suggest the role of Ki-67 as a prognostic factor, some authors have concluded that the Ki-67 labeling index may be utilized to establish indications for chemotherapy and clinically follow post-operative patients. Though no prospective trials exist, Vilar et al. [28] have postulated that tumors with high Ki-67 may respond better to chemotherapy. Certainly, the role of Ki-67 labeling will continue to expand therapeutic and palliative strategies.

\section{Organ-Related Features of Carcinoid Tumors}

Carcinoid tumors have been reported in a wide range of organs but most commonly involve the gastrointestinal tract or bronchopulmonary system. The clinical nature-namely aggressiveness or metastatic potential—and prognosis of carcinoid tumors vary widely depending on the location of the primary tumor (Figure 1A and 1B).

\section{Bronchopulmonary Carcinoid Tumors}

Pulmonary carcinoid tumors account for 1 to 2 percent of all lung malignancies in adults and approximately 25 to 30 percent of all carcinoid tumors [13,29-30]. In a recent review of data from the SEER registry, Modlin et al demonstrated annual incidence rates of bronchial carcinoids at 0.52 and 0.89 per 100,000 population in white males and females, respectively (the corresponding values for black males and females were somewhat higher, at 0.39 and 0.57 , respectively) [13]. Pulmonary carcinoid tumors are thought to arise from Kulchitsky cells disseminated throughout the bronchopulmonary mucosa [31]. Though these tumors share certain morphologic and biochemical characteristics, confusion has plagued reasonable attempts to devise a classification system for these tumors. In 2004, the WHO devised a new classification for bronchopulmonary carcinoids based upon a spectrum of clinicopathologic entities ranging from hyperplastic neuroendocrine cell lesions (carcinoid tumorlets, diffuse idiopathic pulmonary neuroendocrine cell hyperplasia [DIPNECH]) to high-grade neuroendocrine tumors (small cell carcinoma [SCLC] and large cell neuroendocrine carcinoma) [32].

Pulmonary neuroendocrine cell hyperplasia and tumorlets (typical carcinoid tumors that measure $\leq 5 \mathrm{~mm}$ in greatest dimension and extend beyond the basement membrane [33]) represent perhaps the earliest manifestations of neuroendocrine disease in the bronchopulmonary system [34]. The $2004 \mathrm{WHO}$ classification of lung tumors applies the term DIPNECH to a proliferation of scattered single cells, small nodules (neuroendocrine bodies), or linear proliferations of pulmonary neuroendocrine cells confined to the bronchial and bronchiolar epithelium [32]. The clinical relevance of these lesions is controversial. Initially identified in the clinical context of chronic pulmonary diseases like obliterative bronchiolitis, bronchiectasis, and idiopathic pulmonary fibrosis, carcinoid tumorlets were thought to represent benign hyperplastic lesions of little clinical relevance [34]. However, recent data suggest the potential malignant nature of these lesions, as carcinoid tumorlets have been demonstrated in association with typical carcinoid tumors of the bronchopulmonary system and with lymph node metastases [35-38].

Representing nearly two-thirds of pulmonary carcinoids, well-differentiated neuroendocrine tumors of the lungs and bronchi (typical carcinoids) are composed of cytologically bland cells that exhibit minor cellular atypia and rare mitoses [11]. Based on the $2004 \mathrm{WHO}$ classification, these tumors must demonstrate $<2$ mitoses per 10 high power fields (10HPH), lack necrosis, and be larger than $5 \mathrm{~mm}$ [32]. They usually present as perhilar masses in the fifth decade of life and demonstrate a relatively indolent disease course; however, some patients may present with recurrent pneumonia, cough, hemoptysis, and chest pain [39]. Ectopic secretion of biologically 
active hormones is not uncommon, as these tumors may secrete corticotrophin and growth hormone with relative frequency; however, carcinoid syndrome occurs in fewer than 5\% of patients with these tumors [7] due to the relative paucity 5-HT secretion. Metastases from typical pulmonary carcinoids have been reported in approximately $12 \%$ of cases and overall survival is thought to exceed $90 \%[11,22,39-40]$.

Approximately one third of bronchopulmonary carcinoids are atypical tumors, intermediate grade neuroendocrine tumors whose pathologic criteria depends on the presence of carcinoid morphology and at least one of the following: (1) necrosis or (2) 2 to 10 mitoses per $10 \mathrm{HPH}$ [32]. Unlike typical pulmonary carcinoids, atypical carcinoids usually occur in the periphery of the lungs of older patients [41-42]. Their clinical course is aggressive, with a relatively high incidence of mediastinal lymph node metastases (exceeding 50\%) and an abbreviated 5-year survival rate of only $40 \%$ to $75 \%$ [40-42].

\section{Gastric Carcinoid Tumors}

Originating from the histamine-containing enterochromaffin-like (ECL) cells of the embryologic foregut, gastric carcinoid tumors represent approximately $1.8 \%$ of all gastric neoplasms [43] and approximately 7\% of all carcinoids [16]. Because they are most often discovered incidentally during endoscopy, the incidence of gastric carcinoid tumors has increased in recent years as endoscopic technology continues to improve both technologically and diagnostically. Carcinoids of the stomach are generally divided into three distinct groups based on their clinical and histological characteristics: carcinoid tumors associated with chronic atrophic gastritis type A (CAG-A), carcinoid tumors associated with Zollinger-Ellison syndrome (ZES) or MEN-1, and carcinoid tumors which occur sporadically.

Type I gastric carcinoids account for 70 to $80 \%$ of all gastric carcinoids [44]. These tumors are small, benign tumors associated with chronic atrophic gastritis and chronic hypergastrinemia. The relative importance of gastrin in the development of type I gastric carcinoids in lent support by animal studies in which lifelong inhibition of acid secretion in rats induced by potent inhibitors of acid secretion or subtotal fundectomy was found to be associated with the development of carcinoid tumors of ECL cells in the gastric corpus [4547]. To date, however, no cases of carcinoid tumor have been attributed to the use of proton pump inhibitor therapy in humans, suggesting the importance of other factors in the development of type I gastric carcinoids. These tumors often exhibit an indolent disease course and tend to be nonfunctional and asymptomatic [45]. Likewise, metastases are rare, occurring in fewer than 10 percent of tumors less than $2 \mathrm{~cm}$ in greatest dimension [48].

Accounting for approximately 5 percent of gastric carcinoids, type II tumors arise in the setting of MEN-1 and ZES. Like type I gastric carcinoids, they are thought to arise from ECL cells under the influence of hypergastrinemia, resulting in low grade malignant behavior and associated hyperplasia of surrounding ECL cells [11]. Allelic loss of the MEN1 gene locus, a tumor-suppressor gene located on chromosome 11q13, is thought to be involved in the pathogenesis of many of these tumors [49]. Though type II gastric carcinoids are generally indolent and behave similar to type I lesions, these tumors may be large and polypoid, unlike most small type I carcinoids.

Type III gastric carcinoids account for nearly $15 \%$ to $25 \%$ of tumors [47]. They are usually large, solitary, sporadic tumors unassociated with hypergastrinemic states. Sporadic carcinoid tumors may be aggressive, with a high incidence of metastases and a 5-year survival rate of less than 75\% [48]. Unlike type I and II lesions which produce serotonin (5-HT), these tumors are prone to the development of an atypical carcinoid syndrome related to the production of 5hydroxytryptophan (5-HTP), characterized by flushing, hypotension, excessive lacrimation, 
edema, and bronchoconstriction [7]. Excessive production of 5-HTP is thought to be related to the absence of the enzyme aromatic acid decarboxylase, which converts 5-HTP to 5-HT.

\section{Small Intestinal Carcinoid Tumors}

Within the gastrointestinal tract, nearly $45 \%$ of carcinoids arise in the small intestine, making this the most common location for carcinoid tumors [7]. Likewise, carcinoid tumors account for the highest percentage of small bowel tumors, representing approximately one-third of all small intestinal neoplasms [50]. Presumed to arise from the intraepithelial endocrine cells disseminated throughout the intestine, small bowel carcinoids most commonly occur in the distal ileum within $60 \mathrm{~cm}$ of the ileocecal valve [11,13]; moreover, the incidence of these tumors increases with proximity to the cecum. These tumors commonly present in the sixth or seventh decade of life with symptoms of abdominal pain or small bowel obstruction (SBO). SBO has been recognized as an increasing feature of this tumor due to anecdotal evidence of tumor infiltration into the mesentery, provoking an intense fibrotic reaction that results in kinking of the bowel segments with resultant intestinal ischemia (Figure 2). Small bowel carcinoids are frequently multiple, exhibiting multicentricity in up to $30 \%$ of patients [51], and often display metastases to the lymph nodes (39\%) or the liver (31\%) [7]. Development of the typical carcinoid syndrome is rare, manifesting in approximately $5 \%$ to $7 \%$ of patients;

however, younger patients are more likely to develop the carcinoid syndrome and display a worse prognosis [7,52]. Overall 5-year survival is estimated at $65 \%$ and $35 \%$ for locoregional and distant disease, respectively [53].

\section{Appendiceal Carcinoid Tumors}

Thought to arise from the subepithelial endocrine cells in the lamina propria and submucosa, appendiceal carcinoid tumors are the most common neoplasms affecting the appendix [5455]. They are most often discovered during the fourth or fifth decade of life as an incidental finding during surgery performed for other reasons. Most patients with appendiceal carcinoids are asymptomatic, likely due to the location of the neoplasm in relation to the appendiceal base; the vast majority (75\%) are located in the distal third of the appendix, where the risk of obstruction is low, with the remainder located in the middle third, and less than $10 \%$ at the base [11]. In a series of 150 appendiceal carcinoids, Moertel et al demonstrated that most appendiceal neoplasms were less than $1 \mathrm{~cm}$ in largest dimension, though larger tumors $(>2 \mathrm{~cm})$ appeared to be associated with poorer prognosis and increased patient discomfort [56]. In fact, more than $50 \%$ of patients who had large appendiceal carcinoids in one study presented with a clinical picture suggestive of acute appendicitis [57]. The prognosis for tumors less than 2 $\mathrm{cm}$ in size is quite favorable, as few of these neoplasms metastasize. The 5-year survival rate overall is approximately $71 \%$ (94\% for local disease, $85 \%$ for regional metastases, and 34\% in the presence of distal disease) $[7,53]$.

\section{Colonic Carcinoid Tumors}

Carcinoid tumors of the colon are extremely rare tumors, representing less than 11 percent of all carcinoid tumors and only 1 percent of colonic neoplasms [53,58]. Though they are thought to arise from serotonin-producing epithelial endocrine cells disseminated throughout the colon, the carcinoid syndrome is rare in these patients, presenting in fewer than 5\% of cases [59]. Typically, carcinoid tumors of the colon present in the sixth to seventh decade of life during evaluation for anorexia, abdominal pain, and unintentional weight loss [59]. Data from several series demonstrate that carcinoid tumors of the colon are diagnosed late in the course of the disease, and the average size of these tumors was approximately $5 \mathrm{~cm}$ at diagnosis [58-59]. Additionally, at diagnosis, approximately two-thirds of patients have local nodal or distant metastases, resulting in an overall 5-year survival rate of $25 \%$ to $41 \%$ [7]. 


\section{Rectal Carcinoid Tumors}

Most rectal carcinoids are asymptomatic and are discovered incidentally during proctoscopy, sigmoidoscopy, or digital rectal examination. Patients who do have symptoms typically present with rectal pain, bleeding, or constipation. Though these neoplasms represent only $1.3 \%$ of all rectal tumors [53], the true incidence of rectal carcinoids appears to be on the rise due to recent advances in endoscopic technology. Like carcinoids of the small bowel and colon, these tumors are thought to arise from the epithelial endocrine cells; however, unlike these neoplasms, rectal carcinoids contain glucagon and glicentin-related peptides, rather than serotonin [11]. Development of the typical carcinoid syndrome is rare. Interestingly, the size of rectal carcinoids correlates closely with the aggressiveness of the tumor and metastatic potential. Recent series have shown that tumors smaller than $1 \mathrm{~cm}$ rarely metastasize, while lymph node and liver metastases are seen in up to 70\% of cases in which the primary tumor exceeds $2 \mathrm{~cm}$ [13]. Overall 5-year survival rates from the SEER database for localized, regional, or distant disease spread beyond the rectum and rectosigmoid junction over a ten year period were 90 , 49 , and $26 \%$, respectively [13].

\section{Diagnosis}

Carcinoid tumors are rare, slow-growing neoplasms that pose a diagnostic challenge because they are often innocuous at the time of presentation. However, though the initial symptoms of carcinoid may be nonspecific, there are useful diagnostic techniques which may facilitate tumor identification and localization.

\section{Urinalysis}

Traditionally, the biochemical diagnosis of carcinoid tumors has been based on the measurement of serotonin metabolites in a 24-hour urine collection. Elevation of the pharmacologically inactive metabolite of serotonin, 5-hydroxyindoleacetic acid (5-HIAA), in a 24-hour sample has been found to be highly specific (100\%) for the diagnosis of carcinoid disease but lacks sensitivity $(73 \%)[7,60]$. The low sensitivity is not surprising, given that a negative urine 5-HIAA is expected for any patient who has a carcinoid tumor that does not secrete serotonin. Likewise, 5-HIAA levels may be not be elevated in atypical carcinoid disease and may be falsely elevated in other conditions such as celiac sprue, Whipple's disease, and SBO [61]. Importantly, urine 5-HIAA must be performed on a 24-hour urine specimen due to fluctuations in serotonin over the course of a day. Also, there are medications and foods (i.e. avocados, bananas, walnuts, etc.) that can affect the results of the urine 5-HIAA level and should be avoided during the collection. Like 5-HIAA, platelet and urinary serotonin levels are highly specific for carcinoid and may be useful in patients with tumors that produce low levels of serotonin [62]. In fact, recent data suggest the combination of urinary 5-HIAA levels with platelet and urinary serotonin levels results in accurate carcinoid identification in at least $84 \%$ of patients [7].

\section{Serum Analysis}

Serum analysis of chromogranin A ( $\mathrm{CgA})$, the major member of the granin family of acidic secretory glycoproteins that are expressed in NE cells and are cosecreted with bioactive hormones, is perhaps the most specific serum biomarker for carcinoid disease. In a recent series of 238 patients with carcinoid tumors, $\mathrm{CgA}$ levels were found to be much higher in patients with NE disease when compared to healthy control patients ( $p<.001$ ) [63]. Likewise, when comparing all patients without reported neoplasia and patients with NE tumors, specificity of $\mathrm{CgA}$ serum analysis for diagnosis was 84 to $95 \%$ while sensitivity ranged between 75 to $85 \%$. Unlike a urine 5-HIAA test, serum chromogranin testing does not rely on serotonin secretion by the tumor, and therefore it can be a better test for atypical carcinoids and non-secreting tumors. False-positive results may be seen with hepatic or renal failure, inflammatory bowel 
disease, atrophic gastritis, or chronic proton pump inhibitor use [64]. Likewise, a $40 \%$ falsepositive rate has been demonstrated in patients with multiple myeloma [65].

\section{Diagnostic Imaging}

Once the biochemical diagnosis of carcinoid disease is confirmed, a multimodal approach using combinations of imaging studies facilitates tumor localization. Traditionally, abdominal computed tomography (CT) has been the most commonly utilized means of cross-sectional imaging to identify and localized carcinoid tumors and their metastases [7]. Unfortunately, the sensitivity of abdominal CT is poor (44\%-55\%), though recent data suggest the sensitivity of CT may be improving with modern fast, thin-sectional scanners capable of producing multiplanar reconstructions [66]. CT scanning is thought to be especially helpful in identifying locally advanced disease with typical mesenteric involvement, seen as an ill-defined mass near the root of the mesentery with characteristic radiating dense soft tissue strands caused by thickened neurovascular bundles [66]. Likewise, abdominal CT is thought to be helpful in identifying liver metastases [67].

Primary tumors of the small intestine and colon may sometimes be detected by barium studies, which may be undertaken because of symptoms such as abdominal pain or diarrhea.

Characteristically, the tumors appear as submucosal filling defects or polypoidal or ulcerated masses [67]. Within the ileum, luminal narrowing, fold thickening, and spiculation may be seen due to locoregional fibrosis and ischemia. Unfortunately, the findings of barium studies are frequently nonspecific and tumors may be missed.

\section{Nuclear Medicine}

Utilization of radiolabeled receptor-binding peptides and scintigraphy offers considerable diagnostic and therapeutic information in patients with carcinoid tumors. Localization of the primary tumor site with indium-111 (In-111) labeled octreotide (somatostatin receptor scintigraphy [SRS], or Octreoscan) is superior to that of cross sectional imaging with CT or magnetic resonance imaging (MRI). Benefits of Octreoscan include: (1) diagnosis and localization of primary or recurrent carcinoids; (2) prediction of tumor response to octreotide analogue therapy; and (3) staging of carcinoid disease and differentiation from similarappearing benign disease [66]. The diagnostic sensitivity of Octreoscan in patients with asymptomatic gastrointestinal NE tumors has been estimated to be in the range of $80 \%$ to $90 \%$ [68]; fortunately, in those with symptoms of the carcinoid syndrome, sensitivities exceed $90 \%$ [69]. Limitations to octreotide scintigraphy do exist, as Octreoscan is rarely positive in the evaluation of colorectal carcinoids; however, for those primary tumors that are positive, Octreoscan may be predictive of response to somatostatin receptor analogues and may provide a useful tool for follow-up. Importantly, it must be understood that active octreotide therapy for carcinoid syndrome will make an Octreoscan much less useful as there will be receptor saturation.

Metaiodobenzylguanidine (MIBG) scintigraphy, an alternative to Octreoscan, may also be utilized to localize carcinoid disease. Localization with MIBG, a norepinephrine analogue, is believed to be through the reuptake mechanisms regulating norepinephrine entry into the catecholamine storage vesicles of carcinoid tumors [67]. MIBG scans have been found to be positive in $60 \%$ to $70 \%$ of all patients with carcinoid tumors [7], though the reported sensitivity of this test in cases of extra-adrenal carcinoid disease is significantly lower than that of Octreoscan. Interestingly, however, Taal et al demonstrated an overall sensitivity of $95 \%$ for localizing carcinoid disease when MIBG and Octreoscan were used together in 20 patients [70]. 
The role of F-18 labeled fluorodeoxyglucose positron emission tomography (FDG-PET) is unclear in the staging of well-differentiated neuroendocrine tumors; in fact, significant uptake with FDG-PET has not been demonstrated due to the relatively indolent disease course and low metabolic rate of carcinoid tumors. Recent advances in PET tracer development have been promising. Both 18-F-dihydroxy-phenyl-alanine (18F-DOPA) and 11-C-5-hydroxytryptophan (11-C-5-HTP), though not clinically available, have shown improved detection and localization of carcinoid tumors when utilized in combination with high resolution PET [71].

\section{Surgical Treatment}

Effective treatment of carcinoid tumors requires a multidisciplinary approach in which combined modalities are utilized, including surgical resection of the primary tumor and debulking, hepatic chemoembolization, and medical therapy. Though specific treatment decisions are complex and related to the location of primary carcinoid disease and the presence of distal metastases, the preferred initial treatment for carcinoid tumors remains surgical resection. Traditionally, the extent of surgical resection has been dependent on the size of the primary tumor and its location, while location-specific prognosis was commonly based on extent of carcinoid disease, tumor histology, depth of tumor invasion, and gender (Table 2) [7,72-74]. In a more recent SEER database review of over 35,618 patients with NE disease, multivariate analysis revealed that in patients with well-differentiated to moderately differentiated NE tumors, disease stage, primary tumor site, histologic grade, sex, race, age, and year of diagnosis were predictors of outcome $(\mathrm{P}<.001)$ [75].

\section{Bronchopulmonary carcinoid tumors}

Surgical resection is the preferred treatment of bronchopulmonary carcinoid tumors in those patients with adequate functional pulmonary reserve. In patients with relatively small $(<2 \mathrm{~cm})$, localized tumors of the peripheral lunch parenchyma, conservative resection via a wedge or segmental resection has been shown to result in low recurrence rates and excellent long-term survival $[11,39,40,76]$. Tumors with extensive central bronchopulmonary involvement, those with large peripheral parenchymal involvement $(>2 \mathrm{~cm})$, and atypical carcinoids may require more extensive surgical resection with a lobectomy or pneumonectomy [11]. Given the significance of nodal involvement in long term prognostic models of pulmonary carcinoid disease, recent data has demonstrated an advantage to systematic radical mediastinal lymphadenectomy in all patients at the time of initial treatment [77].

\section{Gastric carcinoid tumors}

Recent evidence suggests that type I gastric carcinoids have been over-treated. In a recent multi-institutional study of 65 patients with gastric carcinoid tumors, Borch and colleagues demonstrated that a majority of type I carcinoids were asymptomatic and often detected incidentally at the time of upper endoscopy for other non-related symptoms [44]. As such, tumors less than 1-2 cm in greatest dimension may be clinically observed or removed endoscopically [11,47]. Antrectomy, by eliminating the trophic effect of gastrin, can be useful for large, multiple, or recurrent type I carcinoids [43]. The treatment of type II gastric carcinoids is more complex, largely due to the presence of multicentric disease and relative frequency of distant metastases. Currently, the treatment of type II carcinoids associated with ZES is similar to that of type I tumors; however, when tumor become larger than $2 \mathrm{~cm}$, gastrectomy should be considered [7,47]. Treatment recommendations for type III tumors are universal, given the much poorer prognosis and aggressive nature of these tumors. As such, radical gastrectomy, regardless of tumor size, is the mainstay of current therapy for these lesions [47-48]. 


\section{Small intestinal carcinoid tumors}

Small bowel carcinoids frequently present with nodal and mesenteric metastases, the latter of which may induce an intense local desmoplastic reaction capable of producing small bowel obstruction secondary to fibrosis and ischemia. The surgical management of patients with small bowel carcinoids depends largely on tumor size, location, and metastatic spread [78]. For tumors less than $1 \mathrm{~cm}$ in greatest dimension without evidence of regional lymph node metastases, segmental resection alone with close postoperative surveillance is adequate. A more aggressive surgical approach is necessary for patients with tumors larger than $1 \mathrm{~cm}$, those with locoregional lymph node metastases, or those with mesenteric spread. In these patients, the preferred treatment is a small bowel resection with the associated mesentery and mesenteric lymph nodes [79], the latter of which has been shown to be associated with prolonged diseasefree survival [80]. Importantly, in the presence of aggressive disease, the primary small bowel tumor is often small when compared to the associated regional lymphadenopathy or distant metastases; however, even in the presence of distant disease spread, there is evidence to suggest that outcomes are improved if the primary tumor is resected.

\section{Appendiceal carcinoid tumors}

Tumor size has been shown to be the best predictor of prognosis in patients with appendiceal carcinoid tumors [11]; as such, the surgical management of appendiceal carcinoids depends largely on the size and location of the primary tumor. According to current guidelines, simple appendectomy is adequate for the treatment of small carcinoid tumors $(<1 \mathrm{~cm})$. Indications for more extensive surgery than simple appendectomy have been shown to include tumor size $>2$ $\mathrm{cm}$, lymphatic invasion, lymph node involvement, spread to the mesoappendix, tumor-positive resection margins, and cellular pleomorphism with a high mitotic index [81]. Given that approximately one-third of patients with tumors exceeding $2 \mathrm{~cm}$ in diameter will present or develop nodal and distant metastases, most experts advocate a right hemicolectomy as the appropriate treatment option [56,81-82]. The management of tumors between 1 and $2 \mathrm{~cm}$ continues to be debated; however, a more aggressive treatment algorithm which includes right hemicolectomy is often employed, especially in younger patients [82]. Additional prognostic factors (gender and depth of penetration) may be utilized in choosing between appendectomy and hemicolectomy in these patients[83].

\section{Colorectal carcinoid tumors}

Shebani and colleagues have demonstrated that nearly $55 \%$ of patients with carcinoid tumors involving the colon presented with liver or nodal metastases [83]. Given this propensity for metastatic spread, most experts suggest a formal hemicolectomy with mesenteric resection as the preferred treatment for all carcinoid tumors of the colon. Like appendiceal carcinoids, the size of rectal carcinoid tumors is closely correlated with metastatic risk and long term survival rates. Rectal carcinoids $<2 \mathrm{~cm}$ rarely metastasize, directing the conclusion that for these smaller lesions local excision is sufficient; for lesions $>2 \mathrm{~cm}$, a low anterior resection (LAR) or abdominal perineal resection (APR) should be performed provided distant metastases are absent [84].

\section{Malignant Carcinoid Syndrome and Carcinoid Heart Disease}

The term carcinoid syndrome refers to a constellation of symptoms mediated by various humoral factors, namely serotonin and the tachykinins, elaborated by carcinoid tumors [8586]. In the presence of localized disease, carcinoid neoplasms produce 5-hydroxytryptamine, which is taken up and stored in the platelets while the excesses are inactivated from the liver and lung and transformed into 5-hydroxyindoleacetic acid (5-HIAA). In the presence of liver metastases, however, patients may develop the malignant carcinoid syndrome, which results when vasoactive substances produced by the carcinoid tumor escape hepatic degradation and 
gain access into the systemic circulation. It is also due to the high level of 5-HT degradation by the liver that it is relatively uncommon for disease localized to the gut to display symptoms of serotonin secretion. Clinical findings of the carcinoid syndrome include skin flushing, excessive diarrhea, right-sided heart disease, and bronchoconstriction [7].

Nearly $40 \%$ of patients exhibiting the carcinoid syndrome will develop carcinoid heart disease (CHD) with fibrotic endocardial plaques and associated heart valve dysfunction that classically involves the tricuspid valve [87]. Advanced changes of tricuspid valvular disease has been shown to be associated with poor long-term survival [88], and carcinoid valvular disease, rather than tumor dissemination, is the cause of death in approximately one-third of these patients [89]. Though the mechanism behind CHD is not fully understood, serotonin is presumed to be the catalyst for the cardiac fibrotic process based on murine in vivo models of CHD [90]. Nearly $95 \%$ of patients with present with right-sided heart valve disease, characterized by tricuspid insufficiency and pulmonary stenosis (the so called TIPS process) and the subsequent development of pulmonary hypertension [87]. Left-sided cardiac disease may be seen in up to $10 \%$ of patients, as is commonly associated with angina and coronary vasospasm.

\section{Management of Metastatic Disease}

Surgery is the only way to achieve a complete cure and remains the mainstay of treatment for all patients with primary carcinoid tumors. However, because of the relatively indolent disease course of carcinoid tumors, many patients present with synchronous or metachronous metastatic lesions. In fact, up to $75 \%$ of patients with carcinoid tumors will develop hepatic metastases regardless of the location of the primary tumor [91]. Meeting the goals of carcinoid tumor management—namely symptom control, biochemical control, objective tumor control, and qualityof-life improvement-in patients with widespread disease and/or hepatic metastases relies on a multidisciplinary treatment approach [92].

\section{Surgical Debulking}

Cytoreductive surgery, a mainstay in the management of widely metastatic disease, aims to control symptoms and improve survival by removing or destroying disseminated tumor metastases [78,92]. Although aggressive surgical debulking may not be curative, recent data suggest a significant palliative effect of cytoreduction. In a meta-analysis of cytoreductive partial hepatectomy in patients with advanced, metastatic carcinoid disease, surgical debulking was yielded a 5-year survival rate of over 70\% and complete resolution of carcinoid symptoms in $86 \%$ of patients [93]. Likewise, in another recent study, cytoreductive therapy relieved $83 \%$ of patients of mesenteric ischemia resulting from carcinoid encasement of the mesentery [94].

\section{Somatostatin Analogues}

Somatostatin is a naturally occurring regulatory peptide that acts primarily as a negative regulator of a variety of different cell types, blocking processes such as hormone secretion, cell growth, and smooth muscle contraction. The intracellular functions of somatostatin are initiated by the binding of the peptide to one or more of five different cell-surface receptor proteins-somatostatin subtype receptors 1-5 (SSTR 1-5) - thereby activating one or more intracellular G-proteins and initiating biochemical signaling pathways. To date, two analogues of somatostatin-octreotide, an octapeptide analogue of somatostatin with a relatively short half-life, and lanreotide, a long-acting somatostatin analogue — are commercially available for the treatment of carcinoid tumors [7]. While both analogues bind primarily to receptor subtypes 2, 3, and 5 [95], the clinical efficacy of each seems related to binding of only SSTR 2 [96]. 
Though long-acting somatostatin analogues have been shown to be highly effective in reducing neuroendocrine tumor markers and controlling the symptoms of the carcinoid syndrome [7, 97-98], tumor regression by radiographic criteria is relatively rare (4\%) [99]. However, in a study by Aparacio and colleagues [100], somatostatin analogue therapy stabilized tumor growth in nearly $60 \%$ of patients over a period of 11 months.

Although treatment of patients with carcinoid tumors with daily subcutaneous injections of standard doses of somatostatin analogues may result in significant symptomatic or subjective responses, the median duration of response to standard somatostatin analogue treatment is 12 months [101]. The mechanism for this loss of therapeutic effect with repeated dosing of somatostatin analogue in carcinoid patients—also known as tachyphylaxis—is unknown, though many believe the phenomenon represents SSTR down-regulation or desensitization as a result of prolonged high-dose somatostatin therapy. Recent data by Corleto et al. suggest that single, low-dose administration of octreotide may avoid SSTR desensitization [102].

\section{Systemic Chemotherapeutic Options}

Besides somatostatin analogues, common chemotherapeutic options for metastatic carcinoid syndrome include interferon alfa and cytotoxic agents. The former has been shown to inhibit protein and hormone synthesis in tumor cells, inhibit angiogenesis, and stimulate the immune system [92]. Additionally, interferon alfa has been shown to upregulate the expression of somatostatin receptors and may therefore act synergistically with somatostatin analogues in the treatment of classic carcinoid syndrome [92]. Cytotoxic agents are typically employed as first-line treatments for malignant gastrointestinal NE tumors with elevated proliferation indices (Ki-67 antibody $>5-10 \%$ ). Traditionally, single-agent cytotoxic treatments have produced limited benefit in patients with NE tumors, with response rates of less than $30 \%$ [92]. Therefore, combination therapies - the most common combination of streptozocin, 5-FU, and doxorubicin elicits a response rate in excess of 50\% in malignant pancreatic tumors-are commonly utilized in the treatment algorithms of highly proliferating carcinoid tumors. A list of closed clinical trials, many of which employ a combination therapy approach, is provided (Table 2). Unfortunately, data from many of these studies are currently pending.

\section{Management of Hepatic Metastases}

Many studies have shown that liver resection can play an important role in patients with hepatic metastases from the primary carcinoid tumor, and surgical resection may result in symptom relief and prolonged survival [91]. Though no prospective data exist, retrospective date from Que et al. [103] have demonstrated prolonged survival in patients with metastatic gastrointestinal carcinoid tumors when greater than $90 \%$ of the hepatic metastases were resected. Landry and colleagues [91] confirmed this trend toward improved survival for patients who underwent surgical resection of hepatic metastases, citing a 5-year survival rate of nearly $75 \%$ in these patients.

In patients with hepatic carcinoid metastases who are not candidates for complete surgical resection, several potential therapies-including radiofrequency ablation (RFA) and hepatic chemoembolization - may be offered. RFA provides a novel approach for those with limited hepatic involvement by utilizing selective thermal coagulation of tumor to destroy isolated metastases. In a retrospective study of 73 patients with metastatic foregut or midgut carcinoid tumors or endocrine pancreatic tumors (EPTs), Eriksson and colleagues [104] demonstrated apparently total clearance of liver metastases in $17 \%, 41 \%$, and $46 \%$ of foregut carcinoids, midgut carcinoids, and EPTs, respectively. Likewise, symptom improvement was noted in $71 \%$ patients with carcinoid syndrome, and $75 \%$ also reduced their 5-HIAA and CgA by at least $50 \%$. Similarly, though data in hepatic carcinoid metastases are limited to a few case reports and small series, several studies [105-106] have demonstrated the effectiveness of RFA 
in the treatment of unresectable hepatocellular carcinomas and hepatic metastases of colon carcinoma.

Hepatic chemoembolization (HCE) may be utilized in those with unresectable but liver dominant carcinoid disease. In a report of 20 patients with liver metastases from islet cell tumors of the pancreas or carcinoid tumors, Yao and colleagues [107] demonstrated a significant radiographic response, stabilization of hepatic tumor burden, or improvement of clinical symptoms in $90 \%$ of their cohort. The details of their technique for chemoembolization included cisplatin $(10 \mathrm{mg} / \mathrm{mL}) /$ doxorubicin $(3 \mathrm{mg} / \mathrm{mL}) / \mathrm{mitomycin}-\mathrm{C}(10 \mathrm{mg} / \mathrm{mL})$ combination therapy with either viscous collagen agent or ethiodol and polyvinyl alcohol particles in suspension. Factors related to sustained responses for HCE included previous surgical debulking, $>4$ HCE procedures, and liver metastases of $5 \mathrm{~cm}$ or smaller [107].

\section{Radiolabelled Somatostatin Analogues}

In recent years, several research groups in nuclear medicine and radiopharmacy have sought to develop radiolabelled receptor-binding somatostatin analogues which could act as vehicles to guide radioactivity to SSTR-expressing tissues, such as carcinoid metastases. The first promising dodecanetetraacetic acid-chelated somatostatin analogue- $-{ }^{90} \mathrm{Y}-1,4,7,10-$ tetraazacyclododecane- $N, N$ ', $N$ ", $N$ '”-tetraacetic acid (DOTA) $)^{0}, \mathrm{Tyr}^{3}$, octreotide $\left({ }^{90} \mathrm{Y}\right.$ DOTATOC) — employed the use of a radiolabelled somatostatin analogue couple with ${ }^{90} \mathrm{Y}$, a pure $\beta$-emitter [108]. In a phase II study to evaluate the tumor response of NE tumors to highdose targeted irradiation with ${ }^{90} \mathrm{Y}$-DOTATOC, Waldherr and colleagues [109] demonstrated an objective response rate of $38 \%$ in approximately 13 patients with EPTs,; likewise, a significant reduction in clinical symptoms was noted in these patients. More recently, treatment with ${ }^{177}$ Lu-DOTA ${ }^{0}$, Tyr $^{3}$ octreotate $\left({ }^{177}\right.$ Lu-DOTATATE), a compound with greater SSTR 2 affinity, has been shown to effect complete or partial tumor responses in nearly $30 \%$ of patients with neuroendocrine disease [108]. Importantly, ${ }^{90} \mathrm{Y}$-DOTATOC seems to more effective in larger tumors while ${ }^{177} \mathrm{Lu}$-DOTATATE effects improved tumor response in smaller lesions; as such, combination therapies utilizing both ${ }^{90} \mathrm{Y}$-DOTATOC and ${ }^{177} \mathrm{Lu}$-DOTATATE are currently being explored.

\section{Future Targeted Therapies}

It is well known that the growth, differentiation, phenotype, and hormonal expression of carcinoid tumors depend upon a network of cellular signaling cascades. At this time, several pathways and individual molecules have been implicated in the tumorigenesis of carcinoids and are currently under evaluation. Novel agents targeting the vascular endothelial growth factor (VEGF) and mammalian target of rapamycin (mTOR) have demonstrated promising activity in patients with advanced neuroendocrine tumors. Inhibition of angiogenesis by targeting VEGF is especially promising given the highly vascular nature of neuroendocrine tumors. In our own laboratory, recent data suggest the importance of alternative pathways, which include alterations in raf-1/MEK/ERK activation [110-112], Notch1 activation [113-

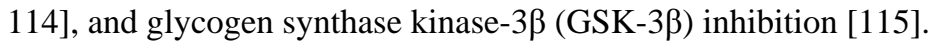

\section{Summary}

Derived from the cells of the disseminated neuroendocrine system, carcinoid tumors are rare, slow-growing neuroendocrine tumors which display a relatively indolent disease course. As such, they are frequently diagnosed late, following the development of widely disseminated metastases. Once metastatic, tumor secretion of various bioactive hormones and peptides cause the debilitating symptoms of malignant carcinoid syndrome. Currently, the only curative therapy remains surgical intervention; however, recent advances which have targeted pathways that regulate carcinoid tumor growth and secretion are promising. Regardless, the prognosis 
and treatment of carcinoid disease is dependent on a multitude of factors, including tumor size, location, patient age, and histology, emphasizing the need to tailor each therapy to the individual patient.

\section{References}

1. Langhans T. Ueber einen Drüsenpolyp im Ileum. Virchows Arch Pathol Anat 1867;38:550-560.

2. Lubarsch O. Ueber dem primären Krebs des Ileum nebst Bemerkungen über das gleichzeitige Vorkommen von Krebs und Tuberculose. Virchows Arch Pathol Anat 1888;111:280-317.

3. Kaplan, EL. The Carcinoid Syndromes. In: Friesen, SR., editor. Surgical Endocrinology: Clinical Syndromes. 1st ed.. Philadelphia, PA: J.B. Lippincott; 1978. p. 120-144.

4. Obendorfer S. Karzinoide tumoren des dunndarms. Frankf Zschr Pathol 1907;1:426-430.

5. Rapport MM, Green AA, Page IH. Serum vasoconstrictor, serotonin; isolation and characterization. J Biol Chem 1948;176:1243-1251. [PubMed: 18100415]

6. Erspamer V, Asero B. Identification of enteramine, the specific hormone of the enterochromaffin cell system, as 5-hydroxytryptamine. Nature 1952;169:800-801. [PubMed: 14941051]

7. Sippel RS, Chen H. Carcinoid Tumors. Surg Oncol Clin N Am 2006;15:463-478. [PubMed: 16882492]

8. Kulchitsky N. Zur Frage über den Bau des Darmkanals. Arch F Mikroskop Anat Bd 1897:49.

9. Liu, C.; Crawford, JM. The Gastrointestinal Tract. Chapter 17. In: Kumar, V.; Abbas, AK.; Fausto, N., editors. Robbins and Cotran Pathologic Basis of Disease. 7th ed.. Philadelphia, PA: Elsevier Saunders; 2005.

10. Robiolio PA, Rigolin VH, Wilson JS, et al. Carcinoid heart disease. Correlation of high serotonin levels with valvular abnormalities detected by cardiac catheterization and echocardiography. Circulation 1995;92:790-795. [PubMed: 7641358]

11. Kulke M, Mayer R. Carcinoid tumors. N Engl J Med 1999;340:858-868. [PubMed: 10080850]

12. Moller J, Connolly H, Rubin J, et al. Factors associated with progression of carcinoid heart disease. N Engl J Med 2003;348:1005-1015. [PubMed: 12637610]

13. Modlin IM, Lye KD, Kidd M. A 5-decade analysis of 13,715 carcinoid tumors. Cancer 2003;97:934959. [PubMed: 12569593]

14. Gustafsson B, Kidd M, Modlin IM. Neuroendocrine tumors of the diffuse neuroendocrine system. Curr Opin Oncol 2008;20:1-12. [PubMed: 18043250]

15. Yao JC, Hassan M, Phan A, et al. One hundred years after "carcinoid": Epidemiology of and prognostic factors for neuroendocrine tumors in 35, 825 cases in the United States. J Clin Oncol 2008;18:3063-3072. [PubMed: 18565894]

16. Maggard MA, O’Connell JB, Ko CY. Updated population-based review of carcinoid tumors. Ann Surg 2004;240:117-122. [PubMed: 15213627]

17. Ogawa H, Nishio A, Satake H, et al. Neuroendcorine tumor of the breast. Radiat Med 2008;26:2832. [PubMed: 18236131]

18. Giordano G, Corcione L, Giordano D, et al. Primary moderately differentiated neuroendocrine carcinoma (atypical carcinoid) of the larynx: A case report with immunohistochemical and molecular study. Auris Nasus Larynx. 2008 [in press].

19. Vidal A, Lorenzo MJ, Isidro ML, et al. Atypical thymic carcinoid in multiple endocrine neoplasia type 1 syndrome. J Endocrinol Invest 2007;30:601-602. [PubMed: 17848844]

20. Anjaneyulu V, Shankar-Swamalatha G, Rao SC. Carcinoid tumor of the gallbladder. Ann Diagn Pathol 2007;11:113-116. [PubMed: 17349570]

21. Williams ED, Sandler M. The classification of carcinoid tumors. Lancet 1963;1:238-239. [PubMed: 14000847]

22. Torre M, Barberis M, Barbieri B, et al. Typical and atypical bronchial carcinoids. Respir Med 1989;83:305-308. [PubMed: 2608951]

23. Soga J, Tazawa K. Pathologic analaysis of carcinoids. Histologic reevaluation of 62 cases. Cancer 1971;28:990-998. [PubMed: 4106849] 
24. Oberg K, Astrup L, Eriksson B, et al. Guidelines for the management of gastroenteropancreatic neuroendocrine tumors (including bronchopulmonary and thymic neoplasms). Part I-general overview. Acta Oncol 2004;43:617-625. [PubMed: 15545182]

25. Sokmensuer C, Gedikoglu G, Uzunalimoglu B. Importance of proliferation markers in gastrointestinal carcinoid tumors: a clinicopathologic study. Hepato-gastroenterol 2001;48:720-723.

26. Kawahara M, Kammori M, Kanauchi H, et al. Immunohistochemical prognostic indicators of gastrointestinal carcinoid tumors. Eur J Surg Oncol 2002;28:140-146. [PubMed: 11884049]

27. Canavese G, Azzoni C, Pizzi S, et al. p27: a potential main inhibitor of cell proliferation in digestive endocrine tumors but not marker of benign behavior. Hum Pathol 2001;32:1094-1101. [PubMed: 11679944]

28. Vilar E, Salazar R, Perez-Garcia J, et al. Chemotherapy and role of proliferation marker Ki-67 in digestive neuroendocrine tumors. Endocr Relat Cancer 2007;14:221-232. [PubMed: 17639039]

29. Quaedvlieg PF, Visser O, Lamers CB, et al. Epidemiology and survival in patients with carcinoid disease in the Netherlands. An epidemiologic study with 2391 patients. Ann Oncol 2001;12:12951300. [PubMed: 11697843]

30. Hemminki K, Li X. Incidence trends and risk factors for carcinoid tumors. Cancer 2001;92:22042210. [PubMed: 11596039]

31. Gould VE, Linnoila RI, Memoli VA, et al. Neuroendocrine components of the bronchopulmonary tract: hyperplasias, dysplasias, and neoplasms. Lab Invest 1983;49:519-537. [PubMed: 6138458]

32. Travis, WD.; Brambilla, E.; Muller-Hermlink, HK., et al. World Health Organization classification of tumors. Pathology and genetics of tumours of the lung, pleura, thymus and heart. Lyon: IARC Press; 2004.

33. Aubry MC, Thomas CF Jr, Jett JR, et al. Significance of multiple carcinoid tumors and tumorlets in surgical lung specimens: analysis of 28 patients. Chest 2007;131:1635-1643. [PubMed: 17400673]

34. Gustafsson BI, Kidd M, Chan A, et al. Bronchopulmonary neuroendocrine tumors. Cancer 2008;113:5-21. [PubMed: 18473355]

35. Felton W, Liebow A, Lindskog G. Peripheral and multiple bronchial adenomas. Cancer 1953;6:555567. [PubMed: 13042778]

36. Bonikos DS, Archibald R, Bensch KG. On the origin of the so-called tumorlets of the lung. Hum Pathol 1976;7:461-469. [PubMed: 939542]

37. D'Agati VD, Perzin KH. Carcinoid tumorlets of the lung with metastasis to a peribronchial lymph node: report of a case and review of the literature. Cancer 1985;55:2472-2476. [PubMed: 3986742]

38. Hausman DH, Weimann RB. Pulmonary tumorlet with hilar lymph node metastasis: report of a case. Cancer 1967;20:1515-1519. [PubMed: 6038395]

39. Okike N, Bernatz PE, Woolner LB. Carcinoid tumors of the lung. Ann Thorac Oncol 1976;22:270277.

40. Chughtai TS, Morin JE, Sheiner NM, et al. Bronchial carcinoid-twenty years' experience defines a selective surgical approach. Surgery 1997;122:801-808. [PubMed: 9347859]

41. Marty-Ane CH, Costes V, Pujol JL, et al. Carcinoid tumors of the lung: do atypical features require aggressive management? Ann Thorac Surg 1995;59:78-83. [PubMed: 7818364]

42. Smolle-Juttner FM, Popper H, Klemen K, et al. Clinical features and therapy of "typical" and "atypical" bronchial carcinoid tumors (grade 1 and grade 2 neuroendocrine carcinoma). Eur J Cardiothorac Surg 1993;7:121-124. [PubMed: 8384862]

43. Hou W, Schubert ML. Treatment of gastric carcinoids. Curr Treat Options Gastroenterol 2007;10:123-133. [PubMed: 17391627]

44. Borch K, Ahrén B, Ahlman H, et al. Gastric carcinoids: biologic behavior and prognosis after differentiated treatment in relation to type. Ann Surg 2005;242:64-73. [PubMed: 15973103]

45. Havu N. Enterochromaffin-like cell carcinoids of gastric mucosa in rats after life-long inhibition of gastric secretion. Digestion 1986;35 Suppl 1:42-55. [PubMed: 3792671]

46. Karnes WE Jr, Walsh JH. The gastrin hypothesis. Implications for antisecretory drug selection. J Clin Gastroenterol 1990;12 Suppl 2:S7-S12. [PubMed: 2246496]

47. Ahlman H. Surgical treatment of carcinoid tumors of the stomach and small intestine. Ital J Gastroenterol Hepat 1999;31 Suppl 2:S198-S201. 
48. Rindi G, Bordi C, Rappel S, et al. Gastric carcinoids and neuroendocrine carcinomas: pathogenesis, pathology, and behavior. World J Surg 1996;20:168-172. [PubMed: 8661813]

49. Debelenko LV, Emmert-Buck MR, Zhuang Z, et al. The multiple endocrine neoplasia type I gene locus is involved in the pathogenesis of type II gastric carcinoids. Gastroenterology 1997;113:773781. [PubMed: 9287968]

50. Barclay TH, Schapira DV. Malignant tumors of the small intestine. Cancer 1983;51:878-881. [PubMed: 6821853]

51. Moertel CG, Sauer WG, Dockerty MB, et al. Life history of the carcinoid tumor of the small intestine. Cancer 1961;14:901-912. [PubMed: 13771655]

52. Yantiss RK, Odze RD, Farraye FA, et al. Solitary versus multiple carcinoid tumors of the ileum: a clinical and pathologic review of 68 cases. Am J Surg Pathol 2003;27:811-817. [PubMed: 12766586]

53. Modlin IM, Sandor A. An analysis of 8305 cases of carcinoid tumors. Cancer 1997;79:813-829. [PubMed: 9024720]

54. Moertel CG, Dockerty MB, Judd ES. Carcnioid tumors of the vermiform appendix. Cancer 1968;21:270-278. [PubMed: 4952505]

55. Lundqvist M, Wilander E. Subepithelial neuroendocrine cells and carcinoid tumours of the human small intestine and appendix: a comparative immunohistochemical study with regard to serotonin, neuron-specific enolase and S-100 protein reactivity. J Pathol 1986;148:141-147. [PubMed: 3512805]

56. Moertel CG, Weiland LH, Nagorney DM, et al. Carcinoid tumor of the appendix: treatment and prognosis. N Engl J Med 1987;317:1699-1701. [PubMed: 3696178]

57. Roggo A, Wood WC, Ottinger LW. carcinoid tumors fo the appendix. Ann Surg 1993;217:385-390. [PubMed: 8466309]

58. Spread C, Berkel H, Jewell L, et al. Colon carcinoid tumors: a population-based study. Dis Colon Rectum 1994;37:482-491. [PubMed: 8181412]

59. Rosenberg JM, Welch JP. Carcinoid tumors of the colon: a study of 72 patients. Am J Surg 1985;149:775-779. [PubMed: 2409828]

60. Feldman JM, O'Dorisio TM. Role of neuropeptides and serotonin in the diagnosis of carcinoid tumors. Am J Med 1986;81:41-48. [PubMed: 2432780]

61. Robertson RG, Geiger WJ, Davis NB. Carcinoid tumors. Am Fam Physician 2006;74:429-434. [PubMed: 16913162]

62. Kema IP, de Vries EG, Schellings AM, et al. Improved diagnosis of carcinoid tumors by measurement of platelet serotonin. Clin Chem 1992;38:534-540. [PubMed: 1373675]

63. Campana D, Nori F, Piscitelli L, et al. Chromogranin A: is it a useful marker of neuroendocrine tumors? J Clin Oncol 2007;25:1967-1973. [PubMed: 17513802]

64. Eriksson B, Oberg K, Stridsberg M. Tumor markers in neuroendocrine tumors. Digestion 2000;62:3338. [PubMed: 10940685]

65. Nobels FR, Kwekkeboom DJ, Coopmans W, et al. Chromogranin A as serum marker for neuroendocrine neoplasia: comparison with neuron-specific enolase and the alpha-subunit of glycoprotein hormones. J Clin Endocrinol Metab 1997;82:2622-2628. [PubMed: 9253344]

66. Tamm EP, Kim EE, Ng CS. Imaging of neuroendocrine tumors. Hematol Oncol Clin North Am 2007;21:409-432. [PubMed: 17548032]

67. Ganim RB, Norton JA. Recent advances in carcinoid pathogenesis, diagnosis and management. Surg Oncol 2000;9:179-179.

68. Kwekkeboom DJ, Krenning EP. Somatostatin receptor imaging. Semin Nucl Med 2002;32:84-91. [PubMed: 11965603]

69. Ramage JK, Davies AH, Ardill J, et al. Guidelines for the management of gastroenteropancreatic neuroendocrine (including carcinoid) tumours. Gut 2005;54 Suppl 4:iv1-iv16. [PubMed: 15888809]

70. Taal BG, Hoefnagel CA, Valdes Olmos RA, et al. Combined diagnostic imaging with 131Imetaiodobenzylguanidine and 111in-pentetreotide in carcinoid tumours. Eur J Can 1996;32A:19241932.

Oncologist. Author manuscript; available in PMC 2010 July 10. 
71. Koopmans KP, Neels OC, Kema IP, et al. Improved staging of patients with carcinoid and islet cell tumors with 18F-dehydroxy-phenyl-alanine and 11C-5-hydroxy-tryptophan positron emission tomography. J Clin Oncol 2008;26:1489-1495. [PubMed: 18349401]

72. Sippel, R.; Chen, H. An update on carcinoid tumors. In: Soper, NJ., editor. Problems in general surgery. Philadelphia: Lippincott Williams \& Wilkins; 2003. p. 125-133.

73. McDermott EW, Guduric B, Brennan MF. Prognostic variables in patients with gastrointestinal carcinoid tumours. Br J Surg 1994;81:1007-1009. [PubMed: 7922047]

74. Rorstad O. Prognostic indicators for carcinoid neuroendocrine tumors of the gastrointestinal tract. $\mathrm{J}$ Surg Oncol 2005;89:151-160. [PubMed: 15719376]

75. Yao JC, Hassan M, Phan A, et al. One hundred years after "carcinoid": epidemiology of and prognostic factors for neuroendocrine tumors in 35,825 cases in the United States. J Clin Oncol 2008;26:30633072. [PubMed: 18565894]

76. Ferguson MK, Landreneau RJ, Hazelrigg SR, et al. Long-term outcome after resection for bronchial carcinoid tumors. Eur J Cardiothorac Surg 2000;18:156-161. [PubMed: 10925223]

77. García-Yuste M, Matillo JM, Cueto A, et al. Typical and atypical carcinoid tumours: analysis of the experience of the Spanish Multi-centric Study of Neuroendocrine Tumours of the Lung. Eur J Cardiothorac Surg 2007;31:192-197. [PubMed: 17196822]

78. Woodside KJ, Townsend CM Jr, Evers BM. Current management of gastrointestinal carcinoid tumors. J Gastrointest Surg 2004;8:742-756. [PubMed: 15358337]

79. Lal A, Chen H. Treatment of advanced carcinoid tumors. Curr Opin Oncol 2006;18:9-15. [PubMed: 16357558]

80. Hellman P, Lundstrom T, Ohrvall U, et al. Effect of surgery on the outcome of midgut carcinoid disease with lymph node and liver metastases. World J Surg 2002;26:991-997. [PubMed: 12016480]

81. Fornaro R, Frascio M, Sticchi C, et al. Appendectomy or right hemicolectomy in the treatment of appendiceal carcinoid tumors? Tumori 2007;93:587-590. [PubMed: 18338494]

82. McGory ML, Maggard MA, Kang H, et al. Malignancies of the appendix: Beyond case series reports. Dis Colon Rectum 2005;48:2264-2271. [PubMed: 16258711]

83. Shebani KO, Souba WW, Finkelstein DM, et al. Prognosis and survival in patients with gastrointestinal tract tumors. Ann Surg 1999;229:815-821. [PubMed: 10363895]

84. Stinner B, Kisker O, Zielke A, et al. Surgical management for carcinoid tumors of the small bowel, appendix, colon, and rectum. World J Surg 1996;20:183-188. [PubMed: 8661815]

85. Bendelow J, Apps E, Jones LE, et al. Carcinoid syndrome. Eur J Surg Oncol 2008;34:289-296. [PubMed: 18068329]

86. Feldman JM. Carcinoid tumors and syndrome. Semin Oncol 1987;14:237-246. [PubMed: 2442815]

87. Gustafsson BI, Hauso O, Drozdov I, et al. Carcinoid heart disease. Int J Cardiol. 2008 [in press].

88. Westberg G, Wangberg B, Ahlman H, et al. Prediction of prognosis by echocardiography in patients with midgut carcinoid syndrome. Br J Surg 2001;88:865-872. [PubMed: 11412260]

89. Oberg K. Neuroendocrine gastrointestinal tumors-a condensed overview of diagnosis and treatment. Ann Oncol 1999;10 Suppl 2:S3-S8. [PubMed: 10399026]

90. Musunuru S, Carpenter JE, Sippel RS, et al. A mouse model of carcinoid heart disease. J Surg Res 2005;126:102-105. [PubMed: 15916982]

91. Landry CS, Scoggins CR, McMasters KM, et al. Management of hepatic metastases of gastrointestinal carcinoid tumors. J Surg Oncol 2008;97:253-258. [PubMed: 18264984]

92. Maroun J, Kocha W, Kvols L, et al. Guidelines for the diagnosis and management of carcinoid tumours. Part 1: The Gastrointestinal tract. A statement from a Canadian National Carcinoid Expert Group. Curr Oncol 2006;13:67-76. [PubMed: 17576444]

93. Que FG, Sarmiento JM, Nagorney DM, et al. Hepatic surgery for metastatic gastrointestinal carcinoid tumors. Cancer Control 2002;9:67-79. [PubMed: 11907468]

94. Boudreaux JP, Putty B, Frey DJ, et al. Surgical treatment of advanced-stage carcinoid tumors: lessons learned. Ann Surg 2005;241:839-846. [PubMed: 15912033]

95. Patel YC, Srikant CB. Subtype selectivity of peptide analogues for all five cloned human somatostatin receptors (hsstr 1-5). Endocrinology 1994;135:2814-2817. [PubMed: 7988476] 
96. Kubota A, Yamada Y, Kagimoto S, et al. Identification of somatostatin receptor subtypes and an implication for the efficacy of somatostatin analogue SMS 201-995 in treatment of human endocrine tumors. J Clin Invest 1994;93:1321-1325. [PubMed: 8132773]

97. Kvols LK, Moertel CG, O'Connell, et al. Treatment of the malignant carcinoid syndrome: evaluation of a long acting somatostatin analogue. N Engl J Med 1986;315:663-666. [PubMed: 2427948]

98. Kvols LK. Therapy of the malignant carcinoid syndrome. Endocrinol Metab Clin N Am 1989;18:557568.

99. Faiss S, Pape UF, Böhmig M, et al. Prospective, randomized, multicenter trial on the antiproliferative effect of lanreotide, interferon alfa, and their combination for therapy of metastatic neuroendocrine gastroenteropancreatic tumors--the International Lanreotide and Interferon Alfa Study Group. J Clin Oncol 2003;21:2689-2696. [PubMed: 12860945]

100. Aparicio T, Ducreux M, Baudin E, et al. Antitumor activity of somatostatin analogues in progressive metastatic neuroendocrine gastroenteropancreatic tumors. Gut 1996;38:430-438. [PubMed: 8675099]

101. de Herder WW, Hofland LJ, van der Lely AJ, et al. Somatostatin receptors in gastroentero-pancreatic neuroendocrine tumours. Endocr Relat Cancer 2003;10:451-458. [PubMed: 14713257]

102. Corleto VD, Angeletti S, Schillaci O, et al. Long-term octreotide treatment of metastatic carcinoid tumor. Ann Oncol 2000;11:491-493. [PubMed: 10847473]

103. Que FG, Nagorney DM, Batts KP, et al. Hepatic resection for metastatic neuroendocrine carcinomas. Am J Surg 1995;169:36-42. [PubMed: 7817996]

104. Eriksson J, Stalberg P, Nilsson A, et al. Surgery and radiofrequency ablation for treatment of liver metastases from foregut and midgut carcinoids and endocrine pancreatic tumors. World J Surg 2008;32:930-938. [PubMed: 18324347]

105. Iannitti DA, Dupuy DE, Mayo-Smith WW, et al. Hepatic radiofrequency ablation. Arch Surg 2002;137:422-426. [PubMed: 11926946]

106. Wong SL, Edwards MJ, Chao C, et al. Radiofrequency ablation for unresectable hepatic tumors. Am J Sur 2001;182:552-557.

107. Yao KA, Talamonti MS, Nemcek A, et al. Indications and results of liver resection and hepatic chemoembolization for metastatic gastrointestinal neuroendocrine tumors. Surgery 2001;130:677685. [PubMed: 11602899]

108. Kaltsas GA, Papadogias D, Makras P, et al. Treatment of advanced neuroendocrine tumours with radiolabelled somatostatin analogues. Endocr relat Cancer 2005;12:683-699. [PubMed: 16322317]

109. Waldherr C, Pless M, Maecke H, et al. Tumor response and clinical benefit in neuroendocrine tumors after 7.4 GBq 90Y-DOTATOC. J Nuc Med 2002;43:610-616.

110. Sippel RS, Carpenter JE, Kunnimalaiyaan M, et al. Raf-1 activation suppresses neuroendocrine marker and hormone levels in human gastrointestinal carcinoid cells. Am J Physiol Gastrointest Liver Physiol 2003;285:G245-G254. [PubMed: 12851216]

111. Kunninmalaiyaan M, Chen H. The raf-1 pathway: a molecular target for treatment of select neuroendocrine tumors? Anticancer Drugs 2006;17:139-142. [PubMed: 16428931]

112. Van Gompel JJ, Kunnimalaiyaan M, Holen K, et al. ZM336372, a Raf-1 activator, suppresses growth and neuroendocrine hormone levels in carcinoid tumor cells. Mol Cancer Ther 2005;4:910-917. [PubMed: 15956248]

113. Kunnimalaiyaan M, Traeger K, Chen H. Conservation of the Notch1 signaling pathway in gastrointestinal carcinoid cells. Am J Physiol Gastrointest Liver Physiol 2005;289:G636-G642. [PubMed: 16160079]

114. Greenblatt DY, Cayo M, Ning L, et al. Suberoyl bishydroxamic acid inhibits cellular proliferation by inducing cell cycle arrest in carcinoid cancer cells. J Gastrointest Surg 2007;11:1515-1520. [PubMed: 17874277]

115. Kunnimalaiyaan M, Ndiaye M, Chen H. Neuroendocrine tumor cell growth inhibition by ZM336372 through alterations in multiple signaling pathways. Surgery 2007;142:959-964. [PubMed: 18063082] 


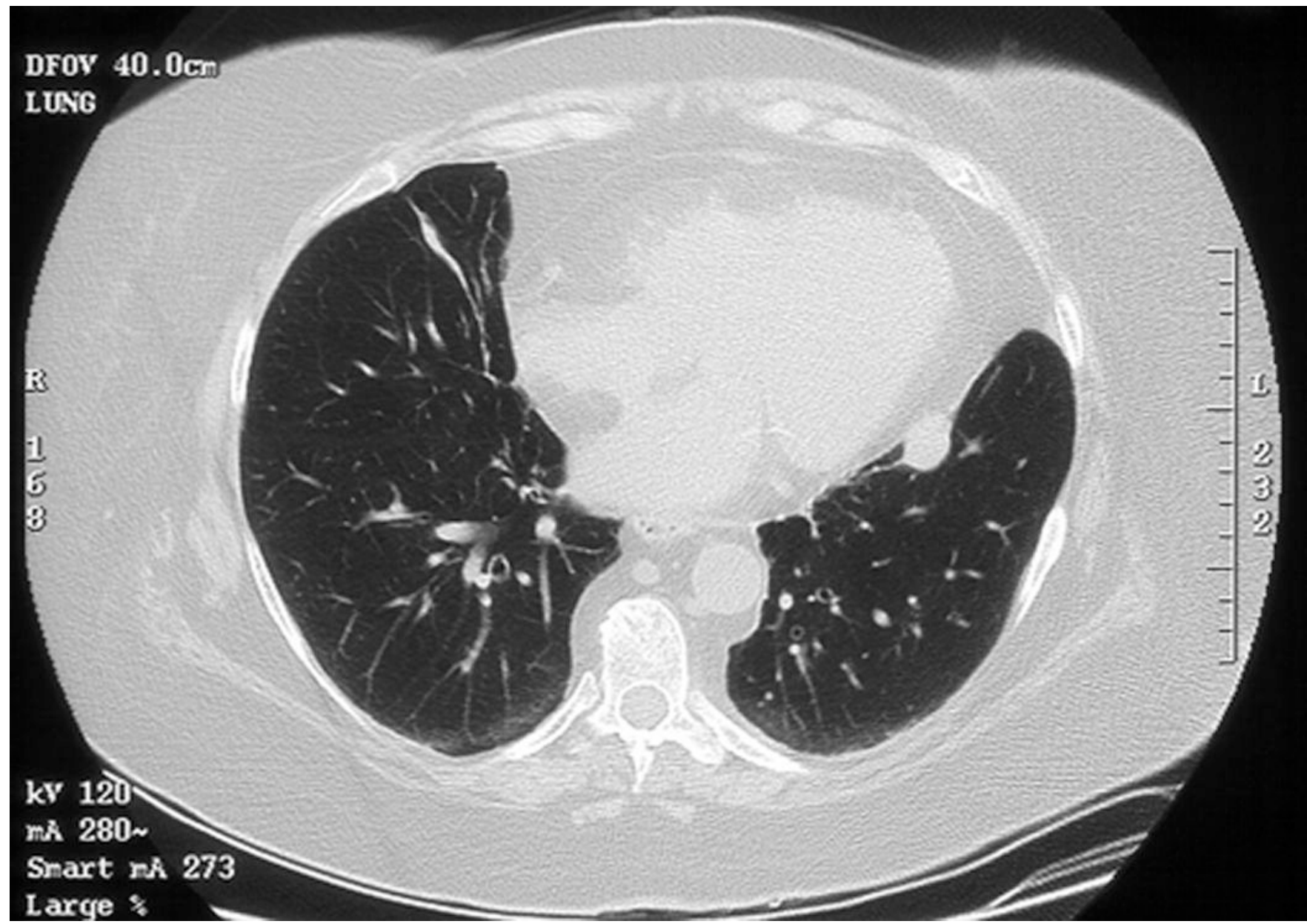




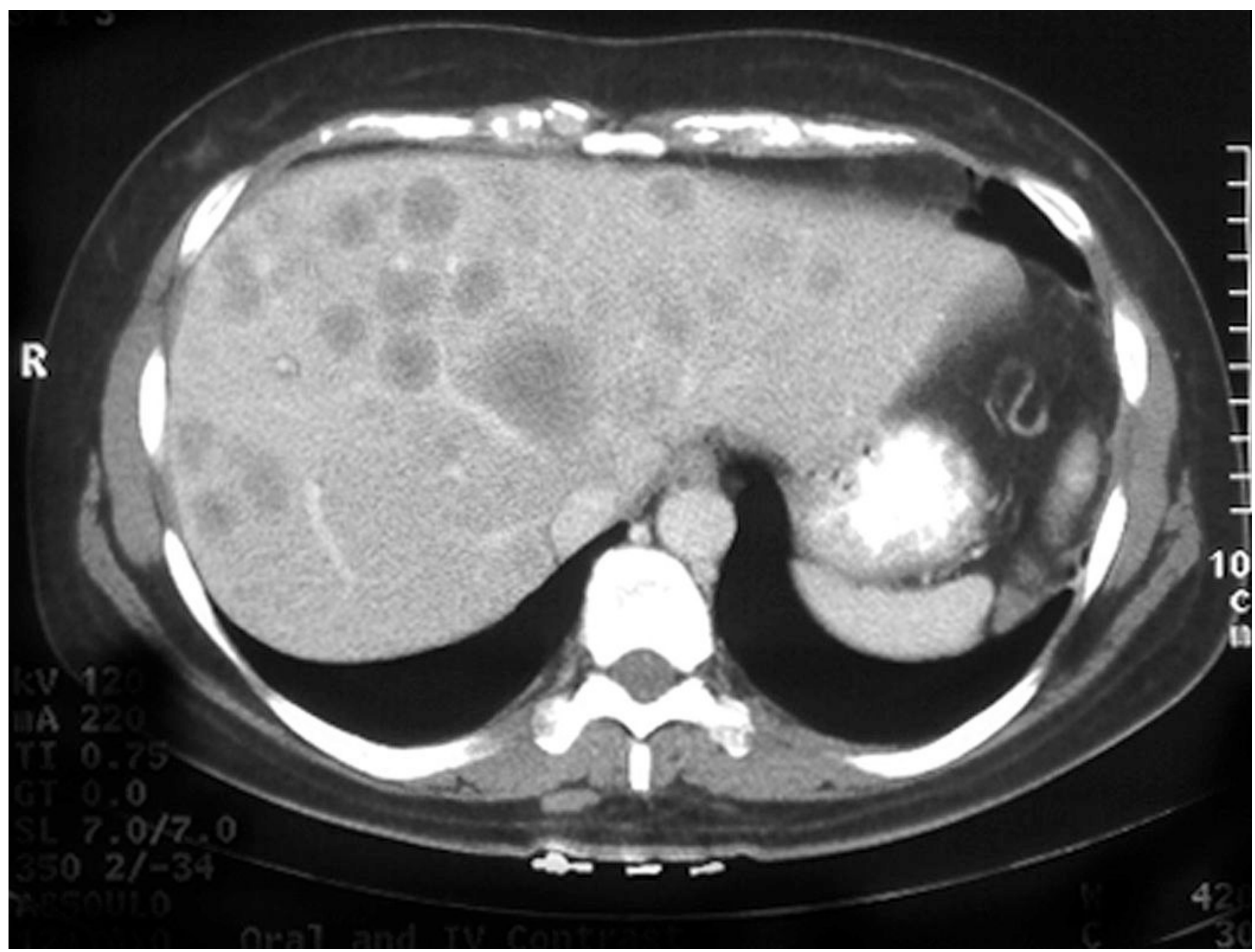

Figure 1. Cross sectional imaging of a carcinoid tumor

(A) CT of the chest showing a solitary left-sided pulmonary carcinoid tumor. Welldifferentiated (typical) pulmonary carcinoid tumors represent nearly two-thirds of all bronchopulmonary carcinoid neoplasms and are commonly found in the perihilar region. (B) $\mathrm{CT}$ of the abdomen showing multiple liver metastases in a patient with metastatic carcinoid disease. (C) CT scan showing the typical appearance of a small bowel carcinoid, represented by a mesenteric soft tissue mass with radiating strands. 


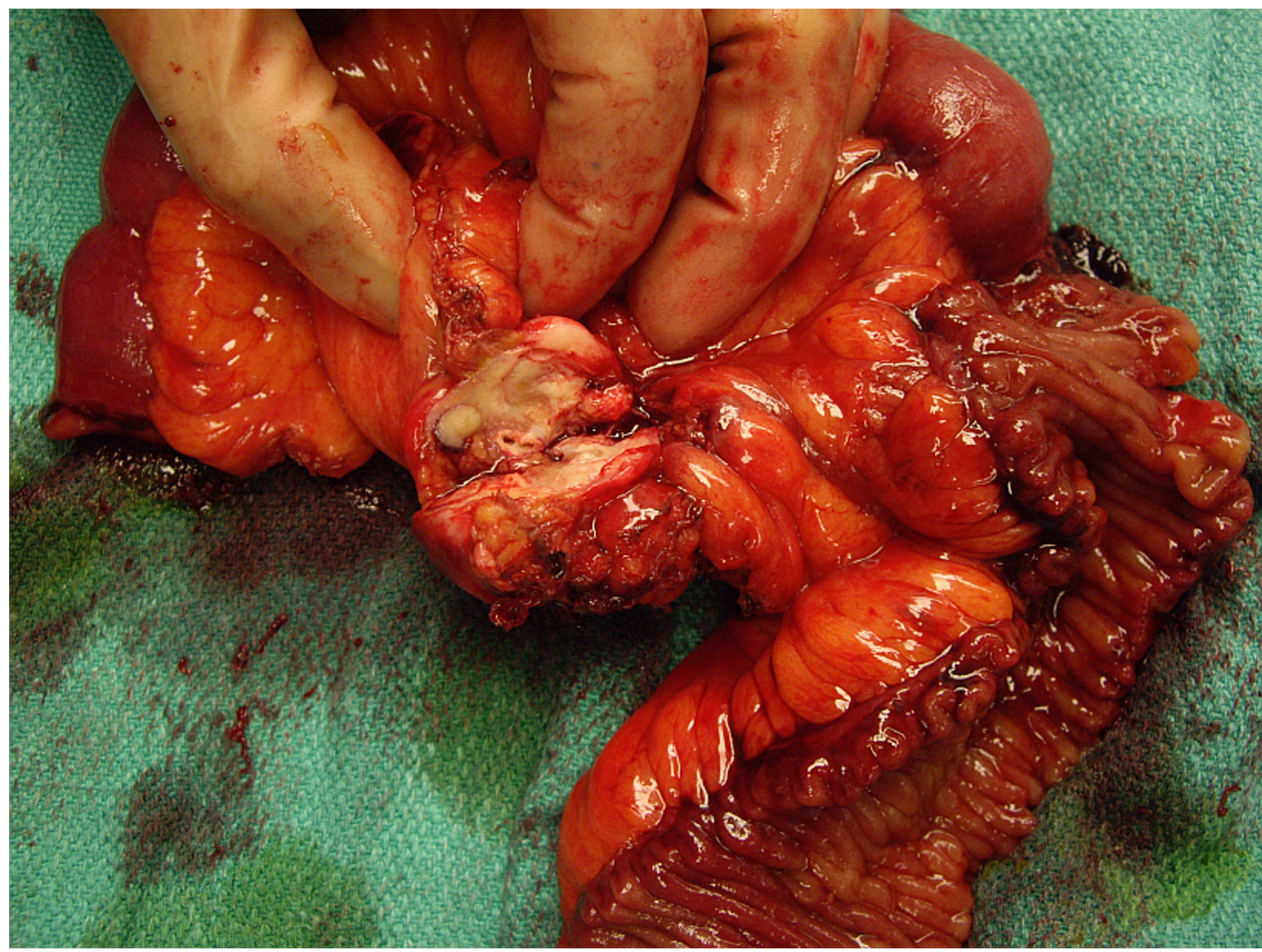

Figure 2. Carcinoid tumor of the small intestine

These tumors are fairly well circumscribed but not encapsulated, white or pale yellow tan, and very firm due to a marked desmoplastic reaction. Carcinoid tumors of the small intestine are frequently associated with mechanical obstruction of the intestine as a result of extensive mesenteric fibrosis (shown here). 
TABLE 1

Common substances secreted by carcinoid tumors

\begin{tabular}{|l|}
\hline Common Secretory Products of Carcinoid Tumors \\
\hline Biogenic Amines \\
\hline 5-hydroxytryptamine (5-HT) \\
\hline 5-hydroxyindoleacetic acid (5-HTP) \\
\hline 5-hydroxytryptophan (5-HTP) \\
\hline Dopamine \\
\hline Histamine \\
\hline Peptides \\
\hline Atrial natriuretic peptide (ANP) \\
\hline Chromogranins A/C \\
\hline$\alpha 1$-antitrypsin \\
\hline Neurotensin \\
\hline Vasoacctive intestinal polypeptide (VIP) \\
\hline Pancreatic polypeptide (PP) \\
\hline Motilin \\
\hline Human chorionic gonadotropin $\alpha / \beta$ \\
\hline Somatostatin \\
\hline Substance P \\
\hline Tachykinins \\
\hline Kallikrein \\
\hline Neuropeptide K \\
\hline Other \\
\hline Prostaglandins \\
\hline
\end{tabular}




\section{TABLE 2}

Combination chemotherapy and single agent clinical trials for patients with gastrointestinal neuroendocrine tumors.

\begin{tabular}{|c|c|c|c|c|}
\hline \multicolumn{5}{|c|}{ Closed or Completed Clinical Trials for Metastatic Carcinoid Disease } \\
\hline $\begin{array}{l}\text { Combination } \\
\text { Chemotherapy }\end{array}$ & Conditions & Phase & Status & Results \\
\hline Everolimus / Octreotide & Malignant carcinoid syndrome & III & $\begin{array}{l}\text { Active, not } \\
\text { recruiting }\end{array}$ & N/A \\
\hline $\begin{array}{l}\text { Bevacizumab / PEG- } \\
\text { Interferon Alfa-2B }\end{array}$ & Gastrointestinal carcinoid tumor & II & Completed & $\begin{array}{l}\text { Objective responses, } \\
\text { reduction of tumor blood } \\
\text { flow, and longer PFS in } \\
\text { patients with BVC than } \\
\text { PEG interferon treatment. }\end{array}$ \\
\hline $\begin{array}{l}\text { Bevacizumab / 2- } \\
\text { methoxyestradiol }\end{array}$ & Carcinoid tumor & II & $\begin{array}{l}\text { Active, not } \\
\text { recruiting }\end{array}$ & N/A \\
\hline $\begin{array}{l}\text { Fluorouracil / Leucovorin / } \\
\text { Irinotecan hydrochloride }\end{array}$ & $\begin{array}{l}\text { Gastrointestinal carcinoid tumor, } \\
\text { islet cell tumor }\end{array}$ & II & $\begin{array}{l}\text { Active, not } \\
\text { recruiting }\end{array}$ & N/A \\
\hline $\begin{array}{l}\text { Filgrastim / Fluorouracil / } \\
\text { Hydroxyurea / } \\
\text { Recombinant interferon alfa }\end{array}$ & Gastrointestinal carcinoid tumor & II & $\begin{array}{l}\text { Active, not } \\
\text { recruiting }\end{array}$ & N/A \\
\hline $\begin{array}{l}\text { Irinotecan hydrochloride / } \\
\text { Oxaliplatin }\end{array}$ & Gastrointestinal carcinoid tumor & II & $\begin{array}{l}\text { Active, not } \\
\text { recruiting }\end{array}$ & N/A \\
\hline RAD001 / Octreotide depot & $\begin{array}{l}\text { Neuroendocrine tumor, islet cell } \\
\text { tumor }\end{array}$ & II & $\begin{array}{l}\text { Active, not } \\
\text { recruiting }\end{array}$ & N/A \\
\hline \multicolumn{5}{|l|}{ Single Agent Chemotherapy } \\
\hline SOM 230 (Pasireotide) & Carcinoid tumor, acromegaly & II & $\begin{array}{l}\text { Active, not } \\
\text { recruiting }\end{array}$ & N/A \\
\hline Thalidomide & $\begin{array}{l}\text { Gastrointestinal carcinoid tumor, } \\
\text { islet cell tumor }\end{array}$ & II & $\begin{array}{l}\text { Active, not } \\
\text { recruiting }\end{array}$ & N/A \\
\hline Romidepsin (FR901228) & $\begin{array}{l}\text { Gastrointestinal carcinoid tumor, } \\
\text { islet cell tumor }\end{array}$ & II & $\begin{array}{l}\text { Active, not } \\
\text { recruiting }\end{array}$ & N/A \\
\hline Temsirolimus (CCI-779) & $\begin{array}{l}\text { Gastrointestinal carcinoid tumor, } \\
\text { islet cell tumor }\end{array}$ & II & $\begin{array}{l}\text { Active, not } \\
\text { recruiting }\end{array}$ & N/A \\
\hline Sorafenib tosylate & $\begin{array}{l}\text { Gastrointestinal carcinoid tumor, } \\
\text { islet cell tumor }\end{array}$ & II & $\begin{array}{l}\text { Active, not } \\
\text { recruiting }\end{array}$ & N/A \\
\hline Gefitinib & $\begin{array}{l}\text { Gastrointestinal carcinoid tumor, } \\
\text { islet cell tumor }\end{array}$ & II & $\begin{array}{l}\text { Active, not } \\
\text { recruiting }\end{array}$ & N/A \\
\hline Recombinant Interleukin-12 & Gastrointestinal carcinoid tumor & I & $\begin{array}{l}\text { Active, not } \\
\text { recruiting }\end{array}$ & N/A \\
\hline Bortezomib & $\begin{array}{l}\text { Gastrointestinal carcinoid tumor, } \\
\text { islet cell tumor }\end{array}$ & II & Completed & $\begin{array}{l}\text { No objective responses in } \\
\text { patients with metastatic } \\
\text { carcinoid or islet cell } \\
\text { tumors. }\end{array}$ \\
\hline
\end{tabular}

